\title{
Estimating Time-Varying Beta of Price Limits and Its Applications in China Stock Market
}

\author{
Rongquan Bai, ${ }^{1}$ Zuoquan Zhang, ${ }^{1}$ and Menggang $\mathrm{Li}^{2}$ \\ ${ }^{1}$ School of Science, Beijing Jiaotong University, Beijing 100044, China \\ ${ }^{2}$ China Center for Industrial Security Research, Beijing 100044, China \\ Correspondence should be addressed to Zuoquan Zhang; zqzhang@bjtu.edu.cn
}

Received 6 December 2012; Accepted 16 June 2013

Academic Editor: Rung Ching Chen

Copyright (c) 2013 Rongquan Bai et al. This is an open access article distributed under the Creative Commons Attribution License, which permits unrestricted use, distribution, and reproduction in any medium, provided the original work is properly cited.

\begin{abstract}
This paper proposes an estimation method of time-varying beta of price limits. It uses China stock market trading data to estimate time-varying beta and researches on systemic risk in China stock market. By comparing prediction errors of market model, SS market model, and Censored-SS market model, it verifies the effectiveness of Censored-SS market model. Furthermore it has some meaningful conclusions in China stock market.
\end{abstract}

\section{Introduction}

Since the foundation of the Capital Asset Pricing Model (CAPM), many researchers focus a great deal of attention on estimating the beta. The most common method of estimating systemic risk is to estimate the slope of CAPM. It is actually a constant and does not vary with time.

In recent years, a growing number of researches have shown that systemic risk of portfolio is unstable, and it will vary with time. There are some works in the literature about estimations of time-varying beta. M-GARCH method, Kalman filtering method, and time-varying market model method proposed by Schwert and Seguin are the most common methods [1].

M-GARCH method was first introduced by Bollerslev [2]. It uses the conditional variance and conditional covariance generated by the multivariate GARCH model to build time-varying beta sequence. Many studies, such as Brooks et al., have applied this method [3-6].

Another method is kalman filtering. It assumes that beta is subjected to a random process firstly. And then it estimates the time-varying beta and generates the relevant parameters of the market model recursively from the initial value. Groenewold and Fraser have studied this method [7].

The third method is extended market model method proposed by Schwert and Seguin. They introduce the heteroscedasticity of comprehensive market volatility and time-varying characteristics of beta to the market model. And the time-varying beta sequence is calculated by estimating the model's parameters. The relevant researches have Episcopos, Reyes, and so on $[8,9]$.

Brooks et al. make a comparison of the three methods in the Australian market. They find that the results of the three methods are significantly different. By comparing the MSEs of estimating betas they believe that kalman filtering is the best method in Australian stock market [10].

Although there have been several estimating methods of time-varying beta and empirical researches of these methods in the literaturs, institutional factors such as price limits' effects on estimation of time-varying beta have not been taken into account. Price limits that restrics daily highest change rate of the stock market are introduced as a mechanism to stabilize the market. Many countries and areas in the world have this restriction, such as China, Australia, France, Japan, and Korea. However, as daily price fluctuation is limited within a predetermined range, it will make the observed return deviate from balanced return and change the random characteristics of return sequence; worse still, instead of using balanced return, using observed return to do the regression estimation leads to a biased estimation of model parameters naturally [11]. So these methods are not suitable for estimating beta of price limits [12-19]. 
Our research will be based on the extended market model proposed and censored model. We call it Censored-SS market model.

\section{Censored-SS Market Model}

2.1. Market Model. Traditional market model is:

$$
R_{i, t}=\alpha_{i}+\beta_{i} R_{m, t}+\varepsilon_{i, t}
$$

where $R_{i, t}$ is the return of portfolio $i$ at $t ; R_{m, t}$ is the return of comprehensive market at $t$; the slope $\beta_{i}$ of regression model is the beta of portfolio $i$, and it represents the systemic risk of portfolio $i$.

The estimation of beta in (1) is

$$
\widehat{\beta}_{i}=\frac{\operatorname{cov}\left(R_{i, t}, R_{m, t}\right)}{\sigma_{m}^{2}},
$$

where the numerator is the covariance between portfolio's return and comprehensive market's return, and the denominator is the variance of comprehensive market' return. So the estimation of beta based on market model is a constant actually, and it will not vary with time.

2.2. Censored Regression Model. Censored regression model is a kind of limited dependent variable models [12]. Censored refers to the observed values of samples in a range that are used by a same value. When regression model is censored, the model is a censored model. Its expression is

$$
\begin{gathered}
y_{i}^{*}=x_{i}^{\prime} \beta+\varepsilon_{i}, \\
y_{i}= \begin{cases}c_{1}, & y_{i}^{*} \leq c_{1}, \\
y_{i}^{*}, & c_{1}<y_{i}^{*}<c_{2}, \\
c_{2}, & y_{i}^{*} \geq c_{2},\end{cases}
\end{gathered}
$$

where $y_{i}^{*}$ is the real dependent variable, $y_{i}$ is the censored dependent variable, $x_{i}$ is the independent variable matrix, $\beta$ is the parametric vector, and $\varepsilon_{i}$ is the disturbance term. $c_{1}$ and $c_{2}$ are two fixed values, and they represent the left and right censored points.

It generally uses the maximum likelihood estimation to estimate (3). Its log-likelihood function is

$$
\begin{aligned}
L(\beta, \sigma)= & \sum_{y_{i}^{*} \leq c_{1}} \log F\left(\frac{c_{1}-x_{i}^{\prime} \beta}{\sigma}\right) \\
& +\sum_{c_{1}<y_{i}<c_{2}} \log f\left(\frac{y_{i}-x_{i}^{\prime} \beta}{\sigma}\right) \\
& +\sum_{y_{i}^{*} \geq c_{2}} \log \left[1-F\left(\frac{c_{2}-x_{i}^{\prime} \beta}{\sigma}\right)\right],
\end{aligned}
$$

where $F$ is the cumulative distribution function of the disturbance item and $f$ is the density function of the disturbance item.
2.3. SS Market Model. Schwert and Seguin proposed a market model of time-varying beta based on market model (namely SS market model) [1]. It is defined as

$$
R_{i, t}=\alpha_{i}+\beta_{i, t} R_{m, t}+\varepsilon_{i, t},
$$

where beta is a variable changing with time. And it can be divided into two parts:

$$
\beta_{i, t}=\beta_{i}+\frac{\delta_{i}}{\sigma_{m, t}^{2}}
$$

where $\beta_{i}$ and $\delta_{i}$ are constants and $\sigma_{m, t}^{2}$ is the conditional variance of comprehensive market return. Equation (6) shows the relationship between systemic risk and comprehensive market fluctuation. If $\delta_{i}>0$, systemic risk and comprehensive market fluctuation have a negative relation, and if $\delta_{i}<0$, systemic risk and comprehensive market fluctuation have a positive relation.

Substituting (6) into (5),

$$
R_{i, t}=\alpha_{i}+\beta_{i} R_{m, t}+\delta_{i} \frac{R_{m, t}}{\sigma_{m, t}^{2}}+\varepsilon_{i, t} .
$$

This is the SS market model, and three are three parameters to be estimated: $\alpha_{i}, \beta_{i}$, and $\delta_{i} . \sigma_{m, t}^{2}$ can be estimated by GARCH model of comprehensive market return, and its estimation can be obtained, $\widehat{\sigma}_{m, t}^{2}$. So the actual estimating equation is

$$
R_{i, t}=\alpha_{i}+\beta_{i} R_{m, t}+\delta_{i} \frac{R_{m, t}}{\widehat{\sigma}_{m, t}^{2}}+\varepsilon_{i, t} .
$$

Equation (8) shows that Schwert and Seguin add timevarying characteristic of beta and heteroscedasticity characteristic of comprehensive market return added in traditional market model actually.

2.4. Return Characteristics of Price Limits. As many countries implement the price limits, there have been some works in the literature that research on return characteristics of price limits; see Wei et al. [12-19]. Market trading price's fluctuation range is generally calculated on the basis of the previous day's closing price. $P_{t-1}$ represents the closing price of trading day $t-1$ that we can observe. And limited rates of price rises and falls are $l_{u}$ and $l_{d}$, respectively. So the closing price of trading day $t$ that we can observe will fall into interval $\left[P_{t-1}\left(1-l_{d}\right), P_{t-1}\left(1+l_{u}\right)\right]$. That is to say, when stock price rises to its daily limit or stock price falls to its daily limit, the balanced closing price $P_{t}^{*}$ will exceed this interval and $P_{t}^{*}$ cannot be observed [20]. The relationship between observed price $P_{t}$ and balanced price $P_{t}^{*}$ can be described as

$$
P_{t}= \begin{cases}P_{t-1}\left(1+l_{u}\right), & P_{t}^{*} \geq P_{t-1}\left(1+l_{u}\right) \\ P_{t}^{*}, & P_{t-1}\left(1-l_{d}\right)<P_{t}^{*}<P_{t-1}\left(1+l_{d}\right) \\ P_{t-1}\left(1-l_{d}\right), & P_{t}^{*} \leq P_{t-1}\left(1-l_{d}\right) .\end{cases}
$$

Equation (9) demonstrates that the observed price will be equal to the balanced price only when the balanced price lies in the predetermined range. 
Equation (9) is divided by $P_{t-1}$ and we take the log of it as follows:

$$
R_{t}= \begin{cases}L_{u}, & \log \left(\frac{P_{t}^{*}}{P_{t-1}}\right) \geq L_{u} \\ \log \left(\frac{P_{t}^{*}}{P_{t-1}}\right), & L_{d}<\log \left(\frac{P_{t}^{*}}{P_{t-1}}\right)<L_{u} \\ L_{d}, & \log \left(\frac{P_{t}^{*}}{L_{d}}\right),\end{cases}
$$

where $R_{t}=\log \left(P_{t} / P_{t-1}\right)$, and it is the observed return; $L_{u}=$ $\log \left(1+l_{u}\right) ; L_{d}=\log \left(1-l_{d}\right)$.

$\log \left(P_{t}^{*} / P_{t-1}\right)$ in (10) can be divided as follows:

$$
\begin{aligned}
\log \left(\frac{P_{t}^{*}}{P_{t-1}}\right) & =\log \left(\frac{P_{t}^{*}}{P_{t-1}^{*}}\right)+\log \left(\frac{P_{t-1}^{*}}{P_{t-1}}\right) \\
& =R_{t}^{*}+L O_{t-1},
\end{aligned}
$$

where $R_{t}^{*}$ is the balanced return of trading day $t ; L O_{t-1}$ is called residual return, and it is equal to $\log \left(P_{t-1}^{*} / P_{t-1}\right)$. When the closing price of trading day $t-1$ does not reach the price limits, because of $P_{t-1}^{*}=P_{t-1}, L O_{t-1}$ will be equal to 0 . When the closing price of trading day $t-1$ reaches the price limits, because of $P_{t-1}^{*} \neq P_{t-1}, L O_{t-1}$ will not be equal to 0 , and it demonstrates that the unrealized return of trading day $t-1$ caused by price limits transfers to the next trading day. We substitute (11) into (10) as follows:

$$
R_{t}= \begin{cases}L_{u}, & R_{t}^{*}+L O_{t-1} \geq L_{u} \\ R_{t}^{*}+L O_{t-1}, & L_{d}<R_{t}^{*}+L O_{t-1}<L_{u} \\ L_{d}, & R_{t}^{*}+L O_{t-1} \leq L_{d} .\end{cases}
$$

Equation (12) is the censored law of price limits. It demonstrates that when the sum of balanced return of trading day $t$ and residual return of trading day $t-1$ is not in $\left(L_{d}, L_{u}\right)$ the observed return will be censored.

2.5. SS Market Model Expansion: Censored-SS Market Model. When stock price of trading day $t-1$ does not reach the price limits, $L O_{t-1}=0$. And (12) becomes

$$
R_{t}= \begin{cases}L_{u}, & R_{t}^{*} \geq L_{u} \\ R_{t}^{*}, & L_{d}<R_{t}^{*}<L_{u} \\ L_{d}, & R_{t}^{*} \leq L_{d}\end{cases}
$$

Like (12), (13) is a censored law. However, when stock price trading day $t-1$ reaches the price limits, $L O_{t-1} \neq 0$, and it will transfer to the next trading day's observed return. It makes the return's censored structure of the latter trading day complicated, as $L O_{t-1}$ cannot be observed.
We cannot apply traditional regression model to the observed return in the censored structure of price limits. In order to apply the censored law to the observed return, we borrow the method of Chen and Jau-Lian $[11,12]$ that deletes the return data of the trading day after the price reaches the price limits. Then the remaining data are the accordance with the censored law.

So we introduce the censored model into the SS market model and we can get a new model. We call it Censored-SS market model. The model is

$$
R_{i, t}^{*}=\alpha_{i}+\beta_{i} R_{m, t}+\delta_{i} \frac{R_{m, t}}{\widehat{\sigma}_{m, t}^{2}}+\varepsilon_{i, t}
$$

where, $R_{i, t}^{*}$ is the implicit dependent variable in censored model. It is subject to the following equations:

$$
R_{i, t}= \begin{cases}L_{u}, & R_{i, t}^{*} \geq L_{u} \\ R_{i, t}^{*}, & L_{d}<R_{i, t}^{*}<L_{u} \\ L_{d}, & R_{i, t}^{*} \leq L_{d} .\end{cases}
$$

So the estimation of (14) is to estimate the SS model. When it is assumed that the error term $\varepsilon_{i, t}$ is subject to a normal distribution, the method to estimate this model is generally maximum likelihood method. Its likelihood function is

$$
\begin{aligned}
& L\left(\alpha_{i}, \beta_{i}, \delta_{i}, \frac{\sigma_{\varepsilon_{i}^{2}}}{R_{i, t}}, \exists t \in H_{n} \cup H_{u} \cup H_{d}\right) \\
& =\prod_{t \in H_{n}} \frac{1}{\sigma_{\varepsilon_{i}}} \phi\left(\frac{R_{i, t}-\alpha_{i}-\beta_{i} R_{m, t}-\delta_{i}\left(R_{m, t} / \widehat{\sigma}_{m, t}^{2}\right)}{\sigma_{\varepsilon_{i}}}\right) \\
& \quad \times \prod_{t \in H_{u}} \frac{1}{\sigma_{\varepsilon_{i}}} \Phi\left(\frac{L_{u}-\alpha_{i}-\beta_{i} R_{m, t}-\delta_{i}\left(R_{m, t} / \widehat{\sigma}_{m, t^{2}}\right)}{\sigma_{\varepsilon_{i}}}\right) \\
& \quad \times \prod_{t \in H_{d}} \frac{1}{\sigma_{\varepsilon_{i}}}\left[1-\Phi\left(\frac{L_{d}-\alpha_{i}-\beta_{i} R_{m, t}-\delta_{i}\left(R_{m, t} / \widehat{\sigma}_{m, t}^{2}\right)}{\sigma_{\varepsilon_{i}}}\right)\right],
\end{aligned}
$$

where $\phi(\cdot)$ and $\Phi(\cdot)$ represent the probability density function and cumulative distribution function of standard normal distribution, respectively. $\sigma_{\varepsilon_{i}^{2}}$ is the variance of disturbance term. $H_{n}$ represents the collection of the trading day that does not reach price limits and trading day before does not reach too. $H_{u}$ represents the collection of trading day that rises to its price limit, but the trading day before does not reach. $H_{d}$ represents the collection of trading day that falls to its price limits, but the trading day before does not reach. The union of $H_{n}, H_{u}$, and $H_{d}$ is the collection of trading days of which the day before does not reach its price limits. 


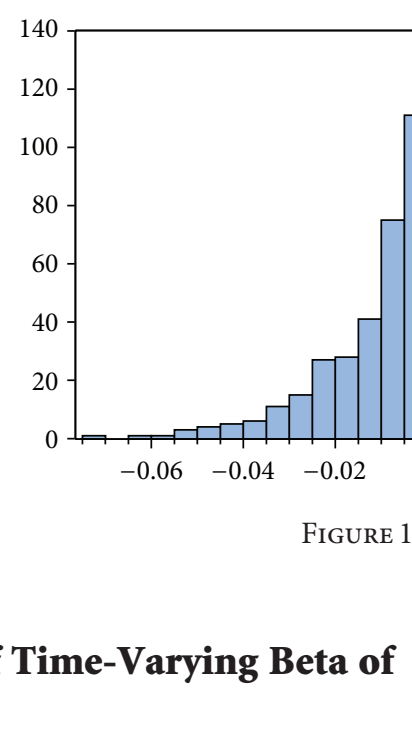

3.1. China Stock Market Background. Now Shanghai and Shenzhen stock exchanges adopt automatic computer exchange system. There are five trading days from Monday to Friday and holidays are excepted. Each trading day is cut off by morning market and afternoon market. Morning market is from 9:30 to 11:30, and afternoon market is from 13:00 to 15:00. From 9:15 to 9:26 is called auction time before morning market, and traders can submit bills, but the bills cannot be completed. Until 9:25, the host computer starts and generates opening prices according to the principal of price and time preference. It uses continuous auction after 9:30. The closing price in Shanghai stock exchange is the average weighted price of all transactions during the last minute. If there are no trades during the day, the closing price is the former trading day's closing price. The closing price in Shenzhen stock exchange is generated by call auction. If call auction cannot generate closing price, the closing price is the average weighted price of all trades during the last minute. If there are no trades during the day, the closing price is the former trading day's closing price [20].

China stock market has daily price limits since 1996. The fluctuation of stock price in a trading day is less than $10 \%$ except that this trading day is the stock's first trading day.

3.2. Data and Sample Selection. All the trading data in this paper are from CSMAR database. The selected period is from the beginning of 2009 to the end of 2011. There are a total of 730 trading days. The comprehensive market return refers to the Shanghai composite index return. The stock objects in this research are limited to the A-shares listed on the Shanghai stock exchange. In order to ensure that all the stock objects have a long enough trading data, we remove the stocks listed after 2009. We classify stocks into large corporations and small corporations and use time-varying beta to research on systemic risk in China stock market. In order to research on systemic risk of China stock market's large corporation and small corporations significantly, this paper sorts the stocks in Shanghai stock exchange according to the total value of trade and selects 30 large corporations and 30 small corporations.
TABLE 1: $R_{m, t}$ 's autocorrelation coefficients and partial correlation coefficients.

\begin{tabular}{lcccc}
\hline Level & $\begin{array}{c}\text { Autocorrelation } \\
\text { coefficient }\end{array}$ & $\begin{array}{c}\text { Partial } \\
\text { correlation } \\
\text { coefficient }\end{array}$ & Q-statistics & Probability \\
\hline 1 & 0.042 & 0.042 & 1.3213 & 0.250 \\
2 & -0.000 & -0.002 & 1.3213 & 0.517 \\
3 & 0.026 & 0.027 & 1.8370 & 0.607 \\
4 & -0.032 & -0.034 & 2.5841 & 0.630 \\
5 & -0.015 & -0.012 & 2.7425 & 0.740 \\
6 & -0.007 & -0.007 & 2.7784 & 0.836 \\
7 & 0.045 & 0.048 & 4.2915 & 0.746 \\
8 & 0.012 & 0.008 & 4.4049 & 0.819 \\
9 & 0.049 & 0.048 & 6.1816 & 0.722 \\
10 & 0.044 & 0.037 & 7.6465 & 0.663 \\
\hline
\end{tabular}

Then we select 10 stocks from them, respectively, which have the most time of reaching price limits as samples.

3.3. Simulation of Market Return's Conditional Variance. The histogram and statistics of the Shanghai composite index's return sequence $R_{m, t}$ from 2009 to 2011 are shown in Figure 1 . The skewness is -0.484593 . Its kurtosis is 4.691811 . Its JarqueBera value is 115.6304 . It means that the distribution of China's stock comprehensive market return is not normal. It is leptokurtic and left skewed. The Shanghai composite index return sequence $R_{m, t}$ 's autocorrelation coefficients and partial correlation coefficients are shown in Table 1. From Table 1 we can find that $R_{m, t}$ does not have serial correlation. So we can fit GARCH models whose conditional mean equation is $R_{m, t}=\mu+\varepsilon_{t}$.

We choose GARCH-M as the autoregressive conditional heteroscedasticity model of comprehensive market return [2].

GARCH-M model's ARCH coefficient $a_{1}$ is 0.037161 . GARCH coefficient $a_{2}$ is $0.940227 . a_{1}+a_{2}=0.977338$. It means that persistence of volatility is 0.977338 . Namely, residual impact still has $0.977338^{5}$ or $89 \%$ after five trading days. 
TABLE 2: The statistics of $\widehat{\sigma}_{m, t}^{2}$.

\begin{tabular}{lcccc}
\hline Mean & Median & Maximum & Minimum & Standard deviation \\
\hline 0.000273 & 0.000216 & 0.001230 & 0.000133 & 0.000157 \\
\hline
\end{tabular}

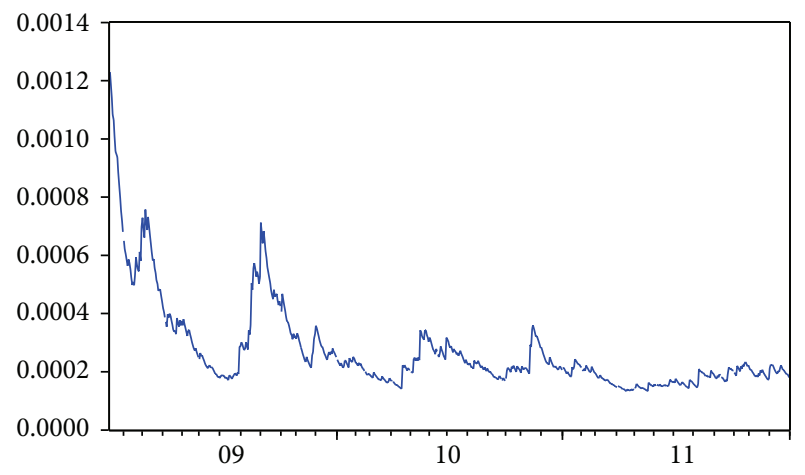

FIGURE 2: The conditional variance $\widehat{\sigma}_{m, t}^{2}$ of comprehensive market return.

Using the selected GARCH-M model we can fit the conditional variance of comprehensive market return within samples. The fitting result of $\widehat{\sigma}_{m, t}^{2}$ sequence is shown in Figure 2. The conditional variance during 2009 is greater, as shown in Figure 2. It means that the comprehensive market has a sharp fluctuation in this period [20]. The descriptive statistics of $\widehat{\sigma}_{m, t}^{2}$ is shown in Table 2.

3.4. Estimation Results. We put the Shanghai composite index return and conditional variance's estimates sequence into (14). And we make use of the large corporations and small corporations' return data to estimate Censored-SS market model, and the results are shown in Table 3. After acquiring each corporation's estimations of $\beta_{i}$ and $\delta_{i}$, we put them into (6). Thus we get the estimated sequence of each stock's time-varying beta of price limits. The descriptive statistics is shown in Tables 4 and 5.

\section{Research on Systemic Risk in China Stock Market}

According the results of time-varying beta estimated by Censored-SS model, systemic risk in China stock market is analyzed from two aspects that are corporation size and market fluctuation.

4.1. Corporation Size. Tables 4 and 5 show the beta's statistics of large corporations and small corporations, respectively. We use large corporations' beta mean sequences and small corporations' beta mean sequences to do the nonparameter wilcoxon matched pair rank test, and the $z$ value and level of significance are 0.7939 and 0.4274 , respectively. So corporation size has no effects on the mean of systemic risk significantly.

We use large corporations' beta standard deviation sequences and small corporations' beta standard deviation
TABLE 3: Results of Censored-SS model.

\begin{tabular}{lccc}
\hline Number & $\alpha_{i}$ & $\beta_{i}$ & $\delta_{i}$ \\
\hline \multicolumn{3}{c}{ Large corporations } \\
1 & $7.42 E-05$ & 0.998446 & $-5.18 E-06$ \\
2 & -0.001022 & 1.045616 & $-4.26 E-05$ \\
3 & -0.000279 & 0.754530 & $2.21 E-05$ \\
4 & -0.000620 & 1.010184 & $6.20 E-05$ \\
5 & 0.001757 & 0.964994 & $5.06 E-05$ \\
6 & $8.00 E-05$ & 1.078617 & $2.87 E-05$ \\
7 & $6.72 E-05$ & 0.949563 & $4.01 E-05$ \\
8 & -0.000402 & 1.434350 & $-4.71 E-05$ \\
9 & 0.000412 & 1.071771 & $1.92 E-05$ \\
10 & -0.000868 & 1.009653 & $-2.57 E-05$ \\
\hline & & Small corporations & \\
1 & 0.000853 & 1.764856 & -0.000210 \\
2 & 0.000320 & 1.277261 & $-2.71 E-05$ \\
3 & 0.001859 & 1.240980 & $-1.85 E-05$ \\
4 & 0.002455 & 1.241941 & $-7.61 E-05$ \\
5 & 0.000430 & 0.766067 & $4.56 E-05$ \\
6 & 0.001145 & 1.028433 & $6.92 E-06$ \\
7 & 0.000543 & 1.277040 & -0.000105 \\
8 & 0.000659 & 1.077382 & $6.54 E-06$ \\
9 & 0.000725 & 1.340762 & $-1.78 E-05$ \\
10 & 0.000209 & 1.191594 & $-2.47 E-05$ \\
\hline & & &
\end{tabular}

sequences to do the nonparameter wilcoxon matched pair rank test, and the $z$ value and level of significance are 0.1134 and 0.9097 , respectively. So corporation size has no effects on the fluctuation of systemic risk significantly.

4.2. Market Fluctuation. $\delta_{i}$ represents the relationship between systemic risk and market fluctuation. If $\delta_{i}>0$, systemic risk and market fluctuation have a negative relation, and if $\delta_{i}<0$, systemic risk and market fluctuation have a positive relation. Table 6 shows the statistics of $\delta_{i}$. From Table 6 we can see that there is only a slight difference between large corporations' $\left|\delta_{i}\right|$ and small corporations' $\left|\delta_{i}\right|$. We use large corporations' $\left|\delta_{i}\right|$ sequences and small corporations' $\left|\delta_{i}\right|$ sequences to do the nonparameter wilcoxon matched pair rank test, and the $z$ value and level of significance are 0.1134 and 0.9097 , respectively. So market fluctuation's effect on the absolute level of systemic risk has no difference between different corporation sizes.

From Table 6 we can also see that the mean of large corporations' $\delta_{i}$ is positive and the mean of small corporations' $\delta_{i}$ is negative. And six stocks of large corporations have positive $\delta_{i}$ and four stocks of large corporations have negative $\delta_{i}$. However, three stocks of large corporations have positive $\delta_{i}$ and seven stocks of large corporations have 
TABle 4: The descriptive statistics of time-varying beta of large corporations.

\begin{tabular}{lcccc}
\hline Number & Mean & Maximum & Minimum & Standard deviation \\
\hline 1 & 0.975618 & 0.994234 & 0.959502 & 0.007778 \\
2 & 0.857880 & 1.010975 & 0.725347 & 0.063969 \\
3 & 0.851923 & 0.920679 & 0.772501 & 0.033186 \\
4 & 1.283414 & 1.476304 & 1.060600 & 0.093101 \\
5 & 1.187985 & 1.345408 & 1.006140 & 0.075982 \\
6 & 1.205096 & 1.294385 & 1.101955 & 0.043097 \\
7 & 1.126281 & 1.251037 & 0.982171 & 0.060215 \\
8 & 1.226783 & 1.396050 & 1.080249 & 0.070727 \\
9 & 1.156384 & 1.216118 & 1.087384 & 0.028831 \\
10 & 0.896395 & 0.988755 & 0.816439 & 0.038592 \\
\hline Total & 1.076776 & 1.476304 & 0.725347 & 0.166302 \\
\hline
\end{tabular}

TABLE 5: The descriptive statistics of time-varying beta of small corporations.

\begin{tabular}{lcccc}
\hline Number & Mean & Maximum & Minimum & Standard deviation \\
\hline 1 & 0.839398 & 1.594092 & 0.186064 & 0.315097 \\
2 & 1.157833 & 1.255224 & 1.073522 & 0.040694 \\
3 & 1.159452 & 1.225937 & 1.101896 & 0.027780 \\
4 & 0.906573 & 1.180060 & 0.669817 & 0.114274 \\
5 & 0.967024 & 1.108891 & 0.803147 & 0.068474 \\
6 & 1.058929 & 1.080458 & 1.034060 & 0.010391 \\
7 & 0.814311 & 1.191658 & 0.487644 & 0.157671 \\
8 & 1.106203 & 1.126550 & 1.126550 & 0.009821 \\
9 & 1.262318 & 1.326288 & 1.206941 & 0.026729 \\
10 & 1.082743 & 1.171509 & 1.005898 & 0.037090 \\
\hline Total & 1.035478 & 1.594092 & 0.186064 & 0.185705 \\
\hline
\end{tabular}

TABLE 6: The statistics of $\delta_{i}$ estimated by Censored-SS model.

\begin{tabular}{lcc}
\hline & Large corporations & Small corporations \\
\hline & \multicolumn{2}{c}{$\delta_{i}$} \\
Mean & $1.02 E-05$ & $-4.20 E-05$ \\
Maximum & $6.20 E-05$ & $4.56 E-05$ \\
Minimum & $-4.71 E-05$ & -0.00021 \\
Standard deviation & $3.85 E-05$ & $7.26 E-05$ \\
Greater than 0 & 6 & 3 \\
Less than 0 & 4 & 7 \\
\hline & & $\left|\delta_{i}\right|$ \\
Mean & $3.43 E-05$ & $4.89 E-05$ \\
Maximum & $6.20 E-05$ & 0.00021 \\
Minimum & $5.18 E-06$ & $6.54 E-06$ \\
Standard deviation & $1.71 E-05$ & $6.77 E-05$ \\
Greater than 0 & & \\
Less than 0 & & \\
\hline
\end{tabular}

negative $\delta_{i}$. Namely, when market fluctuation is increasing, systemic risk of large corporation is decreasing and systemic risk of small corporation is increasing. So When market fluctuation is increasing, investment portfolio transfers to
TABLE 7: The statistics of RMSE within samples.

\begin{tabular}{lccc}
\hline & $\begin{array}{c}\text { Censored-SS } \\
\text { market model }\end{array}$ & $\begin{array}{c}\text { SS market } \\
\text { model }\end{array}$ & $\begin{array}{c}\text { Market } \\
\text { model }\end{array}$ \\
\hline Mean & 0.026684 & 0.026684 & 0.026766 \\
Maximum & 0.030186 & 0.030194 & 0.030197 \\
Minimum & 0.024953 & 0.024957 & 0.024963 \\
Standard deviation & 0.001592 & 0.001598 & 0.001611 \\
\hline
\end{tabular}

large corporation stock can decrease risk in China stock market.

\section{Comparison of Market Model, SS Market Model, and Censored-SS Market Model}

5.1. Prediction Errors within Samples. In order to compare the three models' prediction error within samples, this paper uses the same samples to estimate market model and SS market model. The three models' descriptive statistics of RMSE are shown in Table 7.

Censored-SS model's RMSE is less than that of SS market model. And SS market model's RMSE is less than that of market model. So when considering the time-varying characteristics, SS market model and Censored-SS market model acquire a more accurate return prediction than market model within samples. And when taking price limits into account, Censored-SS market model acquires a more accurate prediction than SS market model.

So for fitting error of stock return within samples, we believe that the beta estimation of Censored-SS model is more accurate than market model and SS market model.

5.2. Beta. We take ten large corporations and ten small corporations as two combinations. And the combination's time-varying beta sequence is equal to the average sequence of the ten corporations' daily beta, respectively, as shown in Figures 3 and 4 . The blue line represents the constant beta sequence estimated by market model. The green line represents the beta sequence estimated by SS market model. And the red line represents the beta sequence estimated by Censored-SS market model. These two figures show that the beta sequence estimated by SS market model is less than the beta sequence estimated by Censored-SS market model most of the time. In other words, ignoring the price limits will lead to underestimate the time-varying systemic risk.

\section{Conclusion}

This paper proposes an estimation method of time-varying beta of price limits and researches on the systemic risk in China stock market. This paper introduces the three main estimation methods of time-varying beta in the literature firstly. And combined with price limits' effects on stock return, it uses a Censored-SS market model. It uses trading data of China's stock market to estimate time-varying beta. Finally by comparing prediction errors of market model, SS market model, and Censored-SS market model, it verifies 


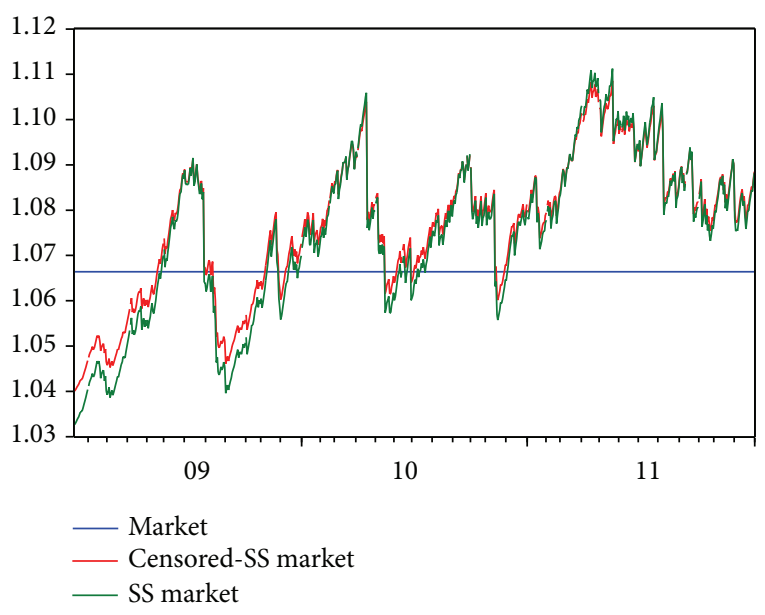

FIGURE 3: Beta sequences of large corporations combination.

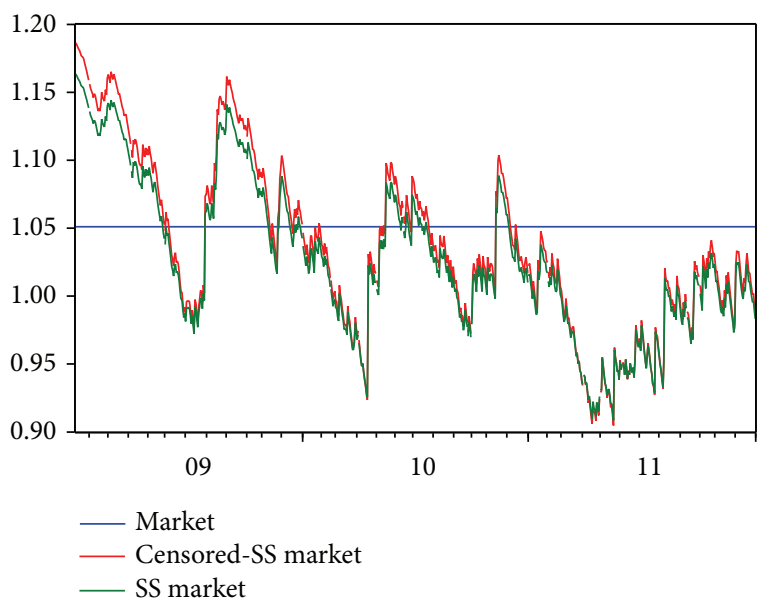

FIGURE 4: Beta sequences of small corporations combination.

the effectiveness of Censored-SS market model. The main conclusions are as follows.

(1) Censored-SS market model can provide more accurate beta estimation than market model and SS market model. Moreover, it will lead to an underestimation of systemic risk when taking the time-varying characteristics into account but ignoring the factor of price limits.

(2) Corporation size has no significant effects on systemic risk's mean and fluctuation in China stock market. However, market fluctuation has different effects on large corporations and small corporation. When market fluctuation increases, large corporation's systemic risk will decrease and small corporation's systemic risk will increase. So the systemic risk gap between large corporations and small corporations will be larger.

\section{Acknowledgment}

The project is supported by the research on China's industrial security index (B09C11010020).

\section{References}

[1] G. W. Schwert and P. J. Seguin, "Heteroskedasticity in stock returns," Journal of Finance, vol. 45, pp. 1129-1155, 1990.

[2] T. Bollerslev, "Generalized autoregressive conditional heteroskedasticity," Journal of Econometrics, vol. 31, no. 3, pp. 307327, 1986.

[3] R. D. Brooks, R. W. Faff, and M. Ariff, "An investigation into the extent of beta instability in the Singapore stock market," Pacific Basin Finance Journal, vol. 6, no. 1-2, pp. 87-101, 1998.

[4] F. Lie, R. Brooks, and R. Faff, "Modeling the equity beta risk of Australian financial sector companies," Australian Economic Papers, vol. 9, pp. 301-311, 2000.

[5] M. D. McKenzie, R. D. Brooks, R. W. Faff, and Y. K. Ho, "Exploring the economic rationale of extremes in GARCH generated betas The case of U.S. banks," Quarterly Review of Economics and Finance, vol. 40, no. 1, pp. 85-106, 2000.

[6] M. D. McKenzie, R. D. Brooks, and R. W. Faff, "The use of domestic and world market indexes in the estimation of timevarying betas," Journal of Multinational Financial Management, vol. 10, no. 1, pp. 91-106, 2000.

[7] N. Groenewold and P. Fraser, "Time-varying estimates of CAPM betas," Mathematics and Computers in Simulation, vol. 48, no. 4-6, pp. 531-539, 1999.

[8] A. Episcopos, "Stock return volatility and time-varying betas in the Toronto stock exchange," Quarterly Journal of Business and Economics, vol. 35, pp. 28-38, 1996.

[9] M. G. Reyes, "Size, time-varying beta, and conditional heteroscedasticity in UK stock returns," Review of Financial Economics, vol. 8, no. 1, pp. 1-10, 1999.

[10] R. D. Brooks, R. W. Faff, and M. D. McKenzie, “Time-varying beta risk of australian industry portfolios: a comparison of modelling techniques," Australian Journal of Management, vol. 23, no. 1, pp. 1-22, 1998

[11] C. Chen and J. Jau-Lian, "The impact of price limits on foreign currency future's price volatility and market efficiency," Global Finance Journal, vol. 7, no. 1, pp. 13-25, 1996.

[12] S. X. Wei, "A censored-GARCH model of asset returns with price limits," Journal of Empirical Finance, vol. 9, no. 2, pp. 197223, 2002.

[13] P.-H. Chou, "A Gibbs sampling approach to the estimation of linear regression models under daily price limits," Pacific Basin Finance Journal, vol. 5, no. 1, pp. 39-62, 1997.

[14] P.-H. Chou, "Modeling daily price limits," International Review of Financial Analysis, vol. 8, no. 3, pp. 283-301, 1999.

[15] H.-C. R. Huang, "Tests of regime-switching CAPM under price limits," International Review of Economics and Finance, vol. 12, no. 3, pp. 305-326, 2003.

[16] Y.-S. Huang, T.-W. Fu, and M.-C. Ke, "Daily price limits and stock price behavior: evidence from the Taiwan stock exchange," International Review of Economics and Finance, vol. 10, no. 3, pp. 263-288, 2001. 
[17] K. A. Kim, "Price limits and stock market volatility," Economics Letters, vol. 71, no. 1, pp. 131-136, 2001.

[18] K. A. Kim and P. Limpaphayom, "Characteristics of stocks that frequently hit price limits: empirical evidence from Taiwan and Thailand," Journal of Financial Markets, vol. 3, no. 3, pp. 315-332, 2000.

[19] S. B. Lee and D. J. Kim, "Price limits and beta," Review of Quantitative Finance and Accounting, vol. 9, no. 1, pp. 35-52, 1997.

[20] C. Lang-Nan, D. Hong-Wei, D. Hong-Gang, H. Zhao-Xia, and C. Deng-Ta, Research on Asset Pricing, China Financial and Economic Publishing House, 2008. 


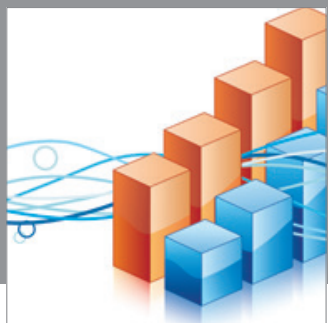

Advances in

Operations Research

mansans

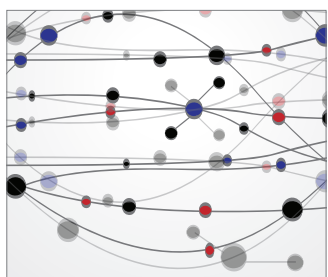

The Scientific World Journal
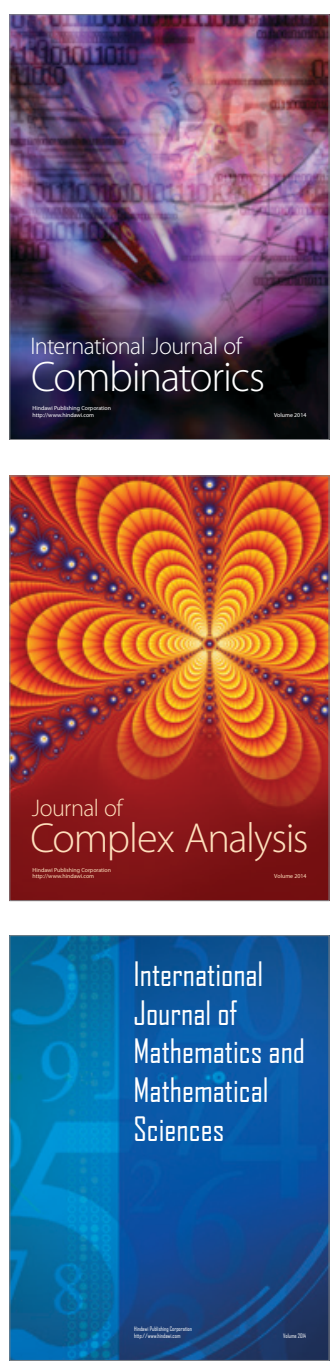
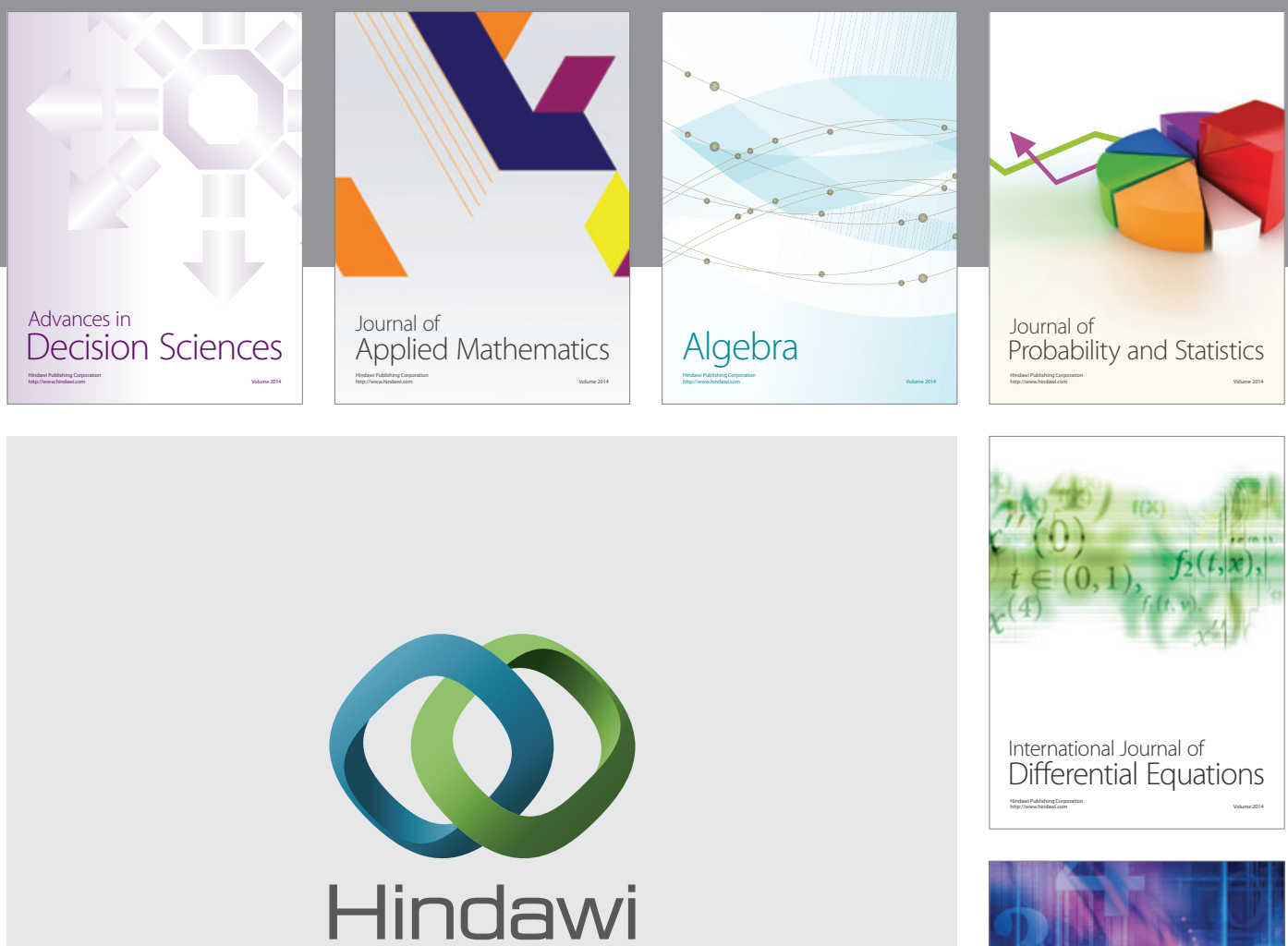

Submit your manuscripts at http://www.hindawi.com
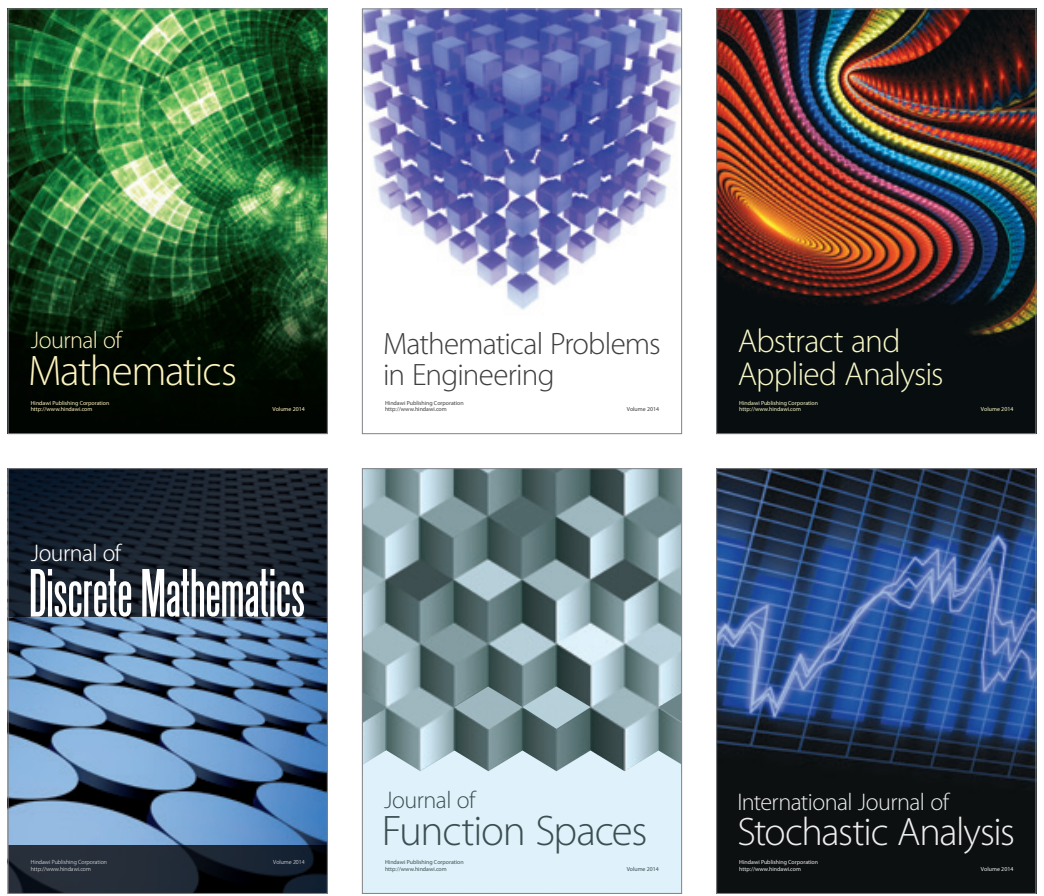

Journal of

Function Spaces

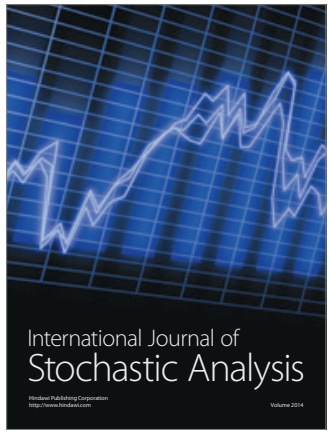

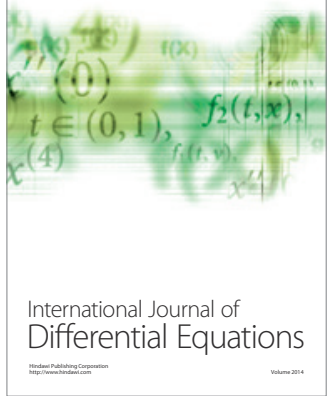
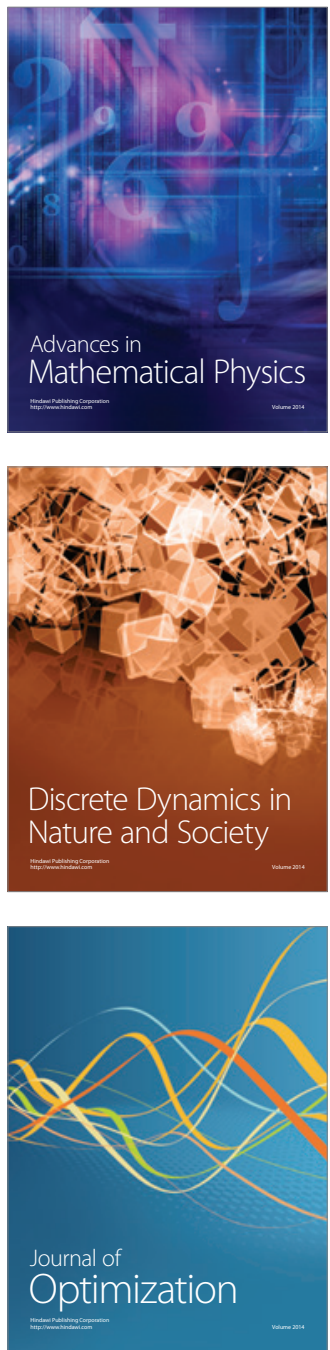